\title{
A Comparative Study on the Framework of Animals Attacking People Report in China and America_-Take the Mainstream Web Portal as an Example
}

\author{
Xun ZAN ${ }^{1}$, Xin $\mathrm{ZHU}^{2}$ \\ ${ }^{1}$ School of Politics and Public Administration, University of Electronic Science and Technology of \\ China, Chengdu, China \\ ${ }^{2}$ School of Politics and Public Administration, University of Electronic Science and Technology of \\ China, Chengdu, China \\ 218282013228@163.com
}

Key words: Framework; Animals Attacking People Report; Web Portals; Content Analysis

\begin{abstract}
This article adopts the content analysis from the perspective of framework theory. Relevant reports from Sohu, Sina and Tencent about tiger attacking people in Ningpo Zoo are used as research sample to be discussed differences and similarities of frameworks with shooting gorillas in American Cincinnati Zoo. It is found that the former obviously differs from the latter in report themes, news sources and report approaches, but there is prominent tendency in both news frameworks. The selection of news source has obvious tendency for tiger attacking people event in Ningpo Zoo and the topic presents the class framework of rights distribution.
\end{abstract}

\section{Issue Introduction}

On January 29, 2017, the event that a tiger bite a man happened in Ningpo Younger Zoo. The man died after being salvaged in hospital and the tiger was shot down. It is announced officially that $\mathrm{Mr}$ Zhang, the victim, did not buy ticket and jump over the wall into the scatter area of tigers. From the date released by the micro-public opinions, the heat zenith of the event reached 89.52 on January 1 . The public opinions were concentrated in a short time, at the same time it became one of the hot topics for the majority of reports from media. As three major web portals, Sohu, Sina and Tencent possessed incomparable power in setting the agenda and guide the social consensus. So what frameworks were applied in the tiger attacking incident of Ningpo Zoo on three web portals?

Similarly, due to the controversial events caused by shooting down animals in zoo, the representative event is shooting the Harlan Bay gorilla in American Cincinnati Zoo (hereinafter referred to as the Harlan Bay event). On May 28, 2016, a 4-year-old boy climbed over the protective fence in the Cincinnati Zoo, fell into the gorilla fence and was caught by a gorilla called Harlan Bay. In order to stop the boy from suffering damage, Harlan Bay was shot down. After the incident broke out, the controversy occurred. On May 29, 2016, a "Facebook" page titled "Seeking Justice for Harlan Bay" received more than 3,000 compliments. Such mainstream portals as Yahoo, America Online and MSNBC made comprehensive follow-up reports on the matter. So what is the similarity and difference of report frameworks between the Harlan Bay and the tiger attacking people events in the Ningpo zoo?

The author adopts the content analysis method from the perspective of framework theory. For the report of event in Ningpo Zoo, from January 29, 2017 to February 14, 2017(14 days), relevant reports (36 articles) in Sohu, Sina and Tencent are selected. And for the Harlan Bay event, from May 28, 2016 to June 11, 2016(14 days), relevant reports (28articles) in Yahoo, American Online and MSNBC are selected.

This article takes examples by the opinions of Ji Linte, defining the framework as some expression way presented by the news text. From following levels, the formation of report theme, selection of news source and report tendency, the concrete representations and tendencies of frameworks are researched in multi-parties dimensions. 


\section{Research Findings}

\section{Relevant Frameworks to Report Topic}

The report focused on the topic of responsibility investigation (47.2) for tiger damaging people in Ningpo Zoo. For example, on January 31, Tencent released "Kinship of victim: the zoo should undertake responsibilities", citing "the zoo should undertake responsibilities and there is bugs in management" to look into the responsible party from victim's families. Secondly, it was the topic about suggestions of incident (22.2), for example, on February 8, "experts talk about tiger attacking in the zoo: visiting the zoo should be also scientific," experts pointed out how to escape from death correctly in the face of the tiger. Thirdly, there was the topic about the incident process $(19.4 \%)$, on January 31 "the man failed to try to stand up after successively kicking tiger head 13 times and feet 3 times", remodeling the incident procedure. The number of topics about incident impacts is the least, accounting for $11.1 \%$ of the total. And on January 31, "Ningpo Zoo will continue to close to launch local inspection," it was reported that "on January 31, 2017, Ningbo Younger Zoo closes".

In terms of frameworks of report topics, there is a significant difference between the Harlan Bay and Ningpo Zoo. Yahoo, America Online and MSNBC primarily concerned with the impact of events (42.8\%), for example, "gorilla world in Cincinnati zoo reopens after the boy fell into fence" and it is reported that "the exhibition of gorilla world has been fitted with a new barrier". Reports about event suggestions were not involved.

\section{Relevant Frameworks to News Source}

The selection of news source reflects the angel and discourse tendency of media(1)according to statistics, among reports for tiger attacking people in Ningpo zoo, "the media" $(52.8 \%)$ is the main provider of the news, due to emergency and significance, domestic famous media reported it most timely and comprehensively, thus media organizations have become an important source of information; This incident is a subject with multiple transmission subject, not only including the official institutions, the media, but experts and zoo and families of victim. Based on the above analysis, the news source (19.4\%) from "others" accounted for the second proportion. The relatives of the deceased, therefore from the "other" sources (19.4\%) occupy the second largest proportion. Multiple sources not only reflect the interaction of multi-agent, but also reflects the balance of the source. The third largest source is experts and scholars $(11.1 \%)$, whose professional interpretation is more persuasive, so they are also important providers of factual source; the fourth largest source is the official institution (8.3\%), when the tiger attacking issue rises to personal safety issues, the official attitude and countermeasures will become focuses of the audience, so the official has also become the more important source of information. However, the news from "families of victim" (5.6\%) and "zoo" (2.8\%) accounted for only 8.4\%.

In addition, in the theme frameworks of responsibility attribution (17 articles), the source for the "media" ( 8 articles), "experts and scholars" (3 articles), the official ( 2 articles)) totally account for $76.5 \%$, and it is seen that representations about "accountability" is almost replaced by high-voice groups (media, experts and scholars, officials).

Different from the report about the tiger attacking in the Ningpo zoo, relevant reports of the Harlan Bay incident were mostly from "official" (32, $1 \%$ of the total). In the official discourse, mainly introduce the explanation to the cause of event from relevant organizations and concrete measures to judge the responsibility and strengthen the safety management. For example, "Jane Goodall Says Zoo Had No Choice But to Kill Harambe the Gorilla", experts on primate believe that "Cincinnati Zoo had no choice but to kill the massive animal to save a child's life.

\section{Relevant Frameworks to Report Tendency}

For the tiger incident in Ningpo zoo, negative reports accounted for $66.7 \%$ of the total, concentrating on causes and impacts to criticize and blame. Positive reports accounted for only 5.6\% of the total, tending to state and express outcomes made after the event. Other objections that do not have any emotional color words are reported in neutral. Neutral coverage accounted for $27.8 \%$ of 
the total with objective and non-emotional presentations. The Harlan Bay incident was also mainly reported negatively (46.4\%), at the same time neutral reports accounted for $42.9 \%$.

In terms of report approaches, the reports of tiger event were more imbalanced. First, sensational coverage covered 20 articles, exceeding 16 articles about rational reports in the number. Secondly, the "responsibility to blame" and "event recommendations" constructed by sensational means accounted for $44.4 \%$ of the total. And the rational report approaches were used in the report about "incident process". For the Harlan Bay incident, rational reports from Yahoo, America Online and MSNBC accounted for 17 articles, and sensational reports 11 articles.

\section{Conclusion}

The framework of topic on the tiger attacking focused on the issue of accountability reported by three web portals. Investigation reasons for the accident and the responsibility has become the main tendency of media coverage. In 36 effective samples, "responsibility" appeared 152 times in total. As long as we are aware of the impact of the event, eventually put into the event reflection; put forward reasonable suggestions to the second tragedy occurring. Therefore, impacts and suggestions on the event should be the emphasis of reports. Otherwise, if blindly investigate accountability and fault, the audience will treat relatives and Younger Zoo as the opposite relationship, not conducive to avoiding the tragedy.

Secondly, for the report of the tiger incident in Ningpo, in the choice of sources, there was clear tendency, because the topic presented the hierarchical framework of power distribution. High-discourse groups, such as experts and scholars, officials and the media (72.2\%), are the main providers of the news, and few information was provided by families and the zoo, showing an overwhelming "power bias" [2], and reflecting power bias and social hierarchical structure. Media, official and scholar groups jointly build a real picture of the tiger attacking the man in Ningpo zoo.

From the perspective of the positive and negative trends reported by the tiger event in Ningbo Zoo, $66.7 \%$ of the total reported negatively, concentrating on causes and impacts to criticize and blame, and the formation of the tendency is not entirely the choice on purpose from the reporter, "but it reveals the social culture in which there exists imbalanced values and rights structure" [3] if this value attitude adds to the report, it is prone to guide the audience to condemn the fault party.

In addition, in terms of report approaches, the reports of tiger event were more imbalanced. Sensational release accounted for $55.6 \%$ of the total, especially on the "responsibility to blame" and "event recommendations". News writers may expect sensational text to provoke the audience's sympathy, consensus or grievances for the responsible party. As a result, for the "emotional" appeal to accountability, the matter on incident process is the response of "routine"

Finally, compared with the report framework of the Harlan Bay incident, it is seen that there are significant differences between two incidents in the topic, the source of the news and the report approaches, but there is similarity in report tendency. For the Harlan Bay incident, Yahoo, America Online and MSNBC mainly concerned about the impact of the incident, reducing the rendering and description for the responsibility to blame. In the report tendency, the report for Harlan Bay incident is more reasonable, 17 rational reports overwhelming 11 sensational reports to guide the audience objectively and rationally observe the incident with an increase of the rational thinking of the incident. Because of its dependence on official sources of information, there is significant bias in the relevant reports on the choice of sources of information.

"Objectivity not only lies in obtaining facts, but through the fact description making the 'avoid block', so that people can understand things beyond the superficial." [4] At most time, news media make people's cognition of the incident further deepen, imperative to cultivate a sense of responsibility, a sense of historical mission and the maintenance of social morality and many other basic social values. Thus in such incidents, journalists should give multiple selections of news source, balance the report topic and tendency within the control, and provide references, enlightenment and reflection for how to prevent the tragedy from taking place again. 


\section{Acknowledgement}

This article is supported by National Social Science Fund: 16BXW022, Ministry of Education Project: 14XJA860001, Sichuan Province Soft Science Project: 17RKX0661

\section{References}

[1] Xu Jiabiao, Han Zhaowei: "legalization of the Reality of the Narrative: Haze Reported the Framework of the Strategy --- to the" China Daily "and" Xi'an Evening News "as an example [J], contemporary communication, 2014

[2]RM Entman: "Democracy without Citizens: Media and the Decay of American Politics", Oxford: Oxford University Press 1989, pp.36.

[3] Qiu Yuchan: "Medical Image of the Media Construction - Medical Disputes Coffin Protest News Analysis" [J] journalism research, 2007.

[4] Shan Bo: "Reconstruction of the Principle of Information Objectivity" [J], Taiwan "Journalism Research", 1998, No. 61. 